Journal Club

Editor's Note: These short, critical reviews of recent papers in the Journal, written exclusively by graduate students or postdoctoral fellows, are intended to summarize the important findings of the paper and provide additional insight and commentary. For more information on the format and purpose of the Journal Club, please see http://www.jneurosci.org/misc/ifa_features.shtml.

\title{
Toward a Model of Retrograde Regulation of Striatal Synaptic Depression
}

\author{
Jesus Bertran-Gonzalez and Ian A. Napier \\ Brain and Mind Research Institute, The University of Sydney, New South Wales 2050, Australia \\ Review of Tozzi et al.
}

As the primary input nucleus of the basal ganglia, the striatum receives considerable glutamatergic information from cortical and thalamic neurons. Most striatal neurons ( $95 \%)$ are GABAergic mediumsized spiny neurons (MSNs), which can be subdivided into two populations according to their projection targets and their selective expression of dopamine receptor types. Striatonigral MSNs express $\mathrm{D}_{1}$-type receptors $\left(D_{1} R s\right)$ and constitute the direct pathway of the basal ganglia, whereas striatopallidal MSNs express $\mathrm{D}_{2}$-type receptors $\left(\mathrm{D}_{2} \mathrm{Rs}\right)$ and constitute the indirect pathway.

An important form of plasticity commonly observed in striatal MSNs, regardless of their projection targets and dopamine receptor types expressed, is a long-lasting reduction of synaptic strength in their excitatory glutamatergic inputs [i.e., longterm depression (LTD)] (Calabresi et al., 1992). LTD in MSNs appears to be initiated by postsynaptic endocannabinoid (eCB) synthesis, which acts as a retrograde signal to reduce glutamate release by activating presynaptic $\mathrm{CB}_{1}$ receptors $\left(\mathrm{CB}_{1} \mathrm{Rs}\right)$. eCB-mediated striatal LTD is strongly dependent upon $\mathrm{D}_{2} \mathrm{R}$ stimulation, as well as

Received March 4, 2011; revised March 29, 2011; accepted March 31, 2011. We thank Prof. M. J. Christie, Prof. B. W. Balleine, and Dr. M. Matamales for their valuable comments on the text.

Correspondence should be addressed to Jesus Bertran-Gonzalez, Behavioural Neuroscience Laboratory, Brain and Mind Research Institute, The University of Sydney, NSW, 2050, Australia. E-mail: j.bertran-gonzalez@ sydney.edu.au.

DOI:10.1523/JNEUROSCI.1133-11.2011

Copyright $\odot 2011$ the authors $\quad 0270-6474 / 11 / 316944-03 \$ 15.00 / 0$ group I metabotropic glutamate receptors $\left(\mathrm{mGluR}_{1 / 5}\right)$ and L-type $\mathrm{Ca}^{2+}$ channels (for review, see Di Filippo et al., 2009). This leaves an important question unanswered: how does a postsynaptically initiated, $\mathrm{D}_{2} \mathrm{R}$-dependent phenomenon induce LTD in all MSNs if $\mathrm{D}_{2}$ Rs are expressed in only a subset of these neurons? Recent studies have attempted to address this question (Wang et al., 2006; Kreitzer and Malenka, 2007; Tozzi et al., 2011).

Wang et al. (2006) suggested that the relevant $\mathrm{D}_{2}$ Rs mediating striatal LTD were those expressed in cholinergic interneurons that, despite their low abundance $(<5 \%)$, project to virtually all MSNs. In their proposed model, stimulation of $\mathrm{D}_{2} \mathrm{Rs}$ in these neurons decreases their firing rate, reducing both acetylcholine (Ach) release and M1type muscarinic Ach receptor $\left(\mathrm{M}_{1} \mathrm{R}\right)$ stimulation. Postsynaptic $M_{1}$ Rs are located near glutamatergic synapses in both direct and indirect pathway MSNs and they inhibit L-type $\mathrm{Ca}^{2+}$ channels (Olson et al., 2005). Therefore, transient interruption of the tonic Ach-mediated $\mathrm{M}_{1} \mathrm{R}$ stimulation would be expected to lead to increased intracellular $\mathrm{Ca}^{2+}$ concentration and local $\mathrm{eCB}$ release in MSNs, which in turn would stimulate presynaptic $\mathrm{CB}_{1} \mathrm{Rs}$ reducing glutamatergic drive in synapses onto both striatonigral and striatopallidal MSN populations.

Contrary to this view, Kreitzer and Malenka (2007) reported that glutamatergic synapses onto $\mathrm{D}_{2} \mathrm{R}$-expressing MSNs were more excitable than those formed onto $\mathrm{D}_{1} \mathrm{R}$-expressing $\mathrm{MSN}$, and that $\mathrm{D}_{2} \mathrm{R}$ stimulation led to eCB-mediated LTD exclusively in striatopallidal neurons, highlighting the role of postsynaptic $\mathrm{D}_{2} \mathrm{Rs}$ in striatal LTD. Selective striatopallidal eCBLTD was also found after mGluR $_{1 / 5}$ stimulation, which led Kreitzer and Malenka (2007) to conclude that eCB-mediated LTD was more likely to occur in indirect pathway neurons.

In a recent paper published in The Journal of Neuroscience, Tozzi et al. (2011) provide a model of $\mathrm{D}_{2} \mathrm{R}$-dependent $\mathrm{eCB}$ mediated LTD that could potentially reconcile the aforementioned studies. The main feature of the Tozzi et al. (2011) model is the involvement of the adenosine $A_{2 A}$ receptors $\left(A_{2 A} R s\right)$, which are highly enriched in the striatum and tightly counteract $\mathrm{D}_{2}$ Rs at multiple levels (Schiffmann et al., 2007). Importantly, $A_{2 A}$ Rs are not only selectively expressed in $\mathrm{D}_{2} \mathrm{R}$-expressing striatopallidal MSNs, but are also expressed presynaptically on corticostriatal and thalamostriatal terminals, where they are thought to modulate glutamate release (Schiffmann et al., 2007; Ferré et al., 2010). Although Tozzi et al. (2011) also examined responses in dopamine-depleted striatal slices (a model of Parkinson's disease), here we will focus on their findings in physiological conditions.

In the first set of experiments, Tozzi et al. (2011) studied the involvement of $\mathrm{D}_{2} \mathrm{Rs}$ and $\mathrm{A}_{2 \mathrm{~A}}$ Rs in eCB-mediated synaptic depression in ex vivo striatal rat slices (Tozzi et al., 2011, their Fig. 1). They performed both intracellular and whole-cell patch-clamp recordings from MSNs of the dorsal striatum. 

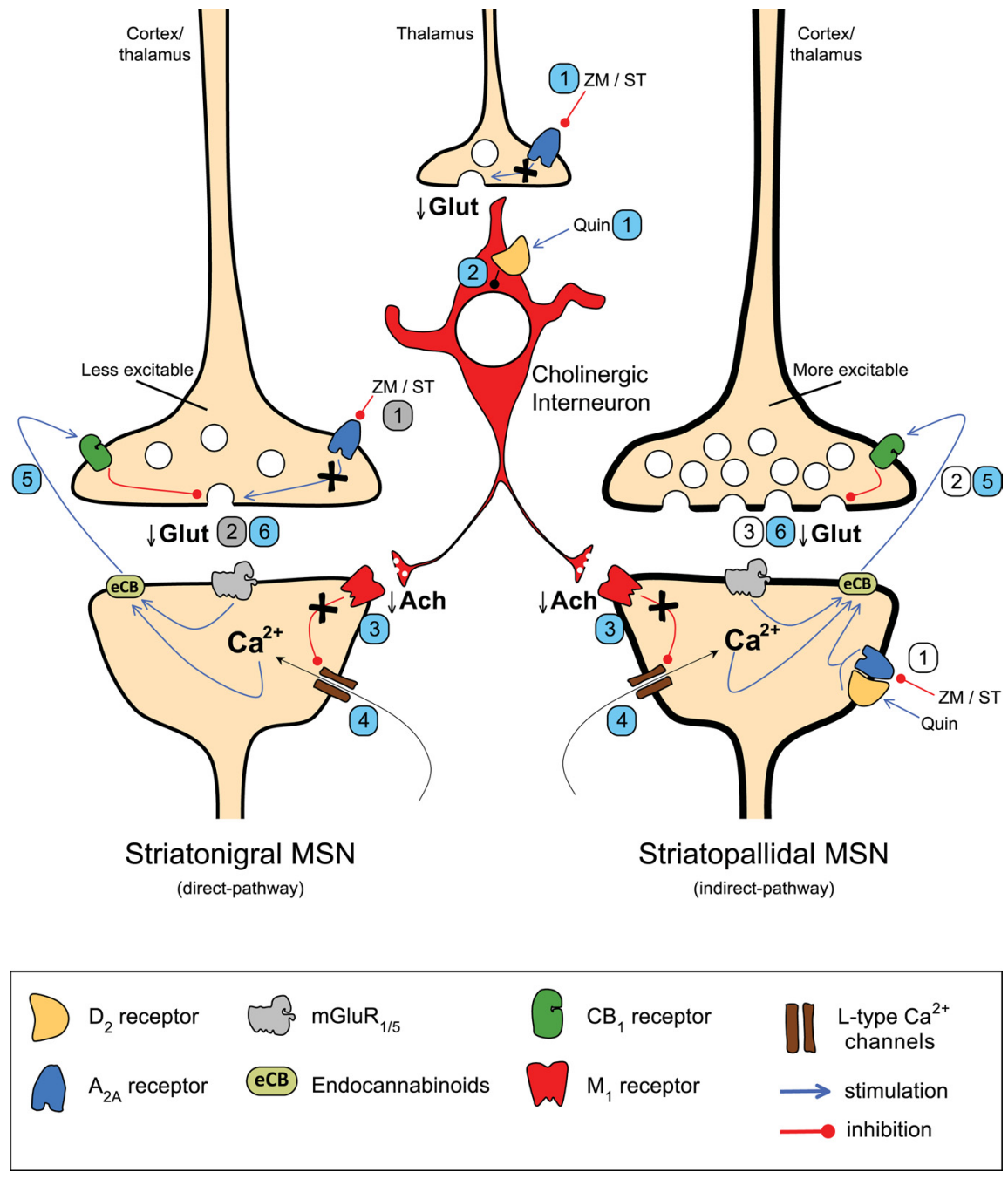

Figure 1. Model of striatal plasticity induced in glutamatergic synapses onto both striatonigral and striatopallidal MSN populations in response to concomitant $\mathrm{D}_{2}$ and $\mathrm{A}_{2 \mathrm{~A}}$ receptor modulation. Coadministration of $\mathrm{D}_{2}$ receptor agonist [quinpirole (Quin)] and $A_{2 A}$ receptor antagonist (ZM or ST) can induce sustained reduction of glutamate release in striatonigral and striatopallidal MSNs through at least three different sequences of events (white, blue, and gray numbered pathways). Postsynaptic modulation of $D_{2} / A_{2 A}$ receptors in striatopallidal neurons may reduce glutamate release ( $\downarrow$ Glut) through local retrograde endocannabinoid signal (white pathway, 1-3). In parallel, blockade of presynaptic $A_{2 A}$ receptors located in glutamatergic terminals onto cholinergic interneurons, plus stimulation of $D_{2}$ receptors expressed in these neurons, may interrupt their firing, ultimately leading to decreased acetylcholine release ( $\downarrow$ Ach, blue pathway, 1-3). The reduced stimulation of $M_{1}$ receptors may remove the inhibition exerted on L-type $\mathrm{Ca}^{2+}$ channels, promoting calcium influx, endocannabinoid production, and reduced glutamate release onto both populations of MSNs (blue pathways 4 -6). Finally, blocking presynaptic $A_{2 A}$ receptors located in glutamatergic terminals onto striatonigral MSNs may additionally reduce the probability of release at these synapses (gray pathway, 1 and 2). Note that, under this scheme, glutamatergic synapses onto both striatonigral and striatopallidal neurons receive at least two different signals that reduce release, in agreement with the equivalent decrease of glutamatergic transmission found by Tozzi et al. (2011) in both MSN populations.

Single $0.1 \mathrm{~Hz}$ stimulations of corticostriatal fibers (in the presence of $\mathrm{GABA}_{\mathrm{A}}$ receptor antagonist bicuculline) were used to induce EPSPs and EPSCs. Once stable recordings were established, the $\mathrm{D}_{2} \mathrm{R}$ agonist quinpirole was applied either alone or in combination with two different $\mathrm{A}_{2 \mathrm{~A}} \mathrm{R}$ antagonists [ZM24138 (ZM) or ST1535 (ST)]. Long-lasting depression of EPSP and EPSC amplitudes, reflecting a decrease in striatal glutamatergic transmission, was produced only when $\mathrm{D}_{2} \mathrm{R}$ agonist and an $\mathrm{A}_{2 \mathrm{~A}} \mathrm{R}$ antagonist were coapplied. Importantly, LTD responses were largely pre- tions in situ (Gong et al., 2003). These mice hold a BAC transgene in which EGFP expression is regulated by $D_{1}$ receptor $\left(D_{1}\right.$ EGFP line) or $\mathrm{D}_{2} \mathrm{R}\left(\mathrm{D}_{2}\right.$-EGFP line) promoter sequences, offering a clear visualization of $\mathrm{D}_{1}$-striatonigral and $\mathrm{D}_{2}$-striatopallidal MSNs, respectively. In these mice, equivalent reductions of EPSC amplitude were observed in $\mathrm{D}_{1}$-EGFP and $\mathrm{D}_{2}$-EGFP MSNs when quinpirole and $\mathrm{ZM}$ were coapplied. Furthermore, the same proportion $(\sim 70 \%)$ of $\mathrm{D}_{1^{-}}$and $\mathrm{D}_{2}$-EGFP neurons showed depressed glutamatergic transmission. These results indicate that concomitant modulation of $\mathrm{D}_{2}$ and $\mathrm{A}_{2 \mathrm{~A}}$ receptors influences plasticity to the same extent in both MSN populations (Fig. 1), in direct contrast to the observations of Kreitzer and Malenka (2007).

To further elucidate the involvement of the eCB system and to confirm a change in presynaptic release, the authors next performed a series of paired-pulse electrophysiology experiments in ex vivo striatal rat slices (Tozzi et al., 2011, their Fig. 3). When quinpirole and ZM or ST were coapplied, the EPSC paired-pulse ratio increased, suggesting a decrease of glutamate release probability. Importantly, $\mathrm{CB}_{1} \mathrm{R}$ antagonist AM251 blocked this effect, pointing to a direct $\mathrm{eCB} / \mathrm{CB}_{1} \mathrm{R}$ involvement in this process. The role of presynaptic $\mathrm{CB}_{1} \mathrm{R}$ was further confirmed through occlusion experiments, in which the $\mathrm{CB}_{1} \mathrm{R}$ agonist WIN reduced EPSC amplitude by itself, an effect that was not strengthened by coapplication of quinpirole and ZM.

Finally, Tozzi et al. (2011) performed $\mathrm{Ca}^{2+}$ buffering studies to explore a possible link between the pharmacological effects of $\mathrm{D}_{2} \mathrm{R} / \mathrm{A}_{2 \mathrm{~A}} \mathrm{R}$ and $\mathrm{eCB}$ retrograde diffusion. Interestingly, inclusion of BAPTA $\left(\mathrm{a} \mathrm{Ca}^{2+}\right.$ chelating agent) in the patch pipette completely prevented the synaptic depression induced by quinpirole plus ZM. Indeed, although not discussed by the authors, quinpirole plus ZM application appeared to initially enhance EPSC amplitude (Tozzi et al., their Fig. 3C). Importantly, intracellular BAPTA did not prevent the intrinsic effects of the $\mathrm{CB}_{1} \mathrm{R}$ and $\mathrm{GABA}_{\mathrm{B}} \mathrm{R}$ agonists WIN and baclofen on EPSC amplitude. Altogether, these results point to the $\mathrm{eCB}$ system as the key mediator of the reduction of synaptic glutamate transmission on presynaptic terminals. As illustrated in Figure 1, this process requires a postsynaptic increase of intracellular $\mathrm{Ca}^{2+}$ in MSNs promoted by $\mathrm{D}_{2} \mathrm{R}$ and $\mathrm{A}_{2 \mathrm{~A}} \mathrm{R}$ modulation (Fig. 1, white numbered pathway).

As mentioned above, previous studies have described an involvement of cholinergic interneurons in $\mathrm{D}_{2}$-dependent and 
eCB-mediated LTD in both striatonigral and striatopallidal MSNs (Wang et al., 2006). To explore whether their observed effect was related to acetylcholinergic neurotransmission, Tozzi et al. (2011) performed whole-cell recordings on cholinergic interneurons and showed that the combination of low-dose quinpirole and ZM reduced the interneurons' tonic firing rate (Tozzi et al., 2011, their Fig. 7). Further, the authors demonstrated that inhibition of $M_{1}$ Rs by pirenzepine prevented EPSC amplitude reduction in MSNs by quinpirole and $\mathrm{ZM}$, an effect that was again rescued by WIN (Tozzi et al., 2011, Fig. 8). In agreement with previous reports (Wang et al., 2006), these findings implicate cholinergic interneurons in the propagation of $\mathrm{D}_{2} \mathrm{R}$-dependent synaptic plasticity to all MSN populations and highlight the role of $\mathrm{A}_{2 \mathrm{~A}} \mathrm{R}$ in this process. This mechanism involves postsynaptic $\mathrm{M}_{1} \mathrm{Rs}$, which, through L-type $\mathrm{Ca}^{2+}$ channels, may ultimately lead to eCB formation and retrograde signaling (Fig. 1, blue numbered pathway).

In building a model encompassing their findings, Tozzi et al., 2011, hypothesized that $\mathrm{D}_{2} \mathrm{R}$ and $\mathrm{A}_{2 \mathrm{~A}} \mathrm{R}$ are coexpressed on striatal cholinergic interneurons, a possibility that was confirmed by triple immunofluorescence studies, in which $\mathrm{D}_{2} \mathrm{R}$ and $\mathrm{A}_{2 \mathrm{~A}} \mathrm{R}$ were colabeled in combination with a marker for cholinergic interneurons (Tozzi et al., 2011, their Fig. 6). However, these results should be considered carefully, since $\mathrm{D}_{2} \mathrm{R}$ and $\mathrm{A}_{2 \mathrm{~A}} \mathrm{R}$ were detected with primary antibodies from the same host, a delicate method that relies on the monovalency of the $\mathrm{F}_{\mathrm{ab}}$ fragment to prevent cross-reactivity, but that may produce interference if not saturated properly (Owen et al., 2010). Despite $\mathrm{D}_{2} \mathrm{R}$ expression in striatal cholinergic interneurons being quite clear, $\mathrm{A}_{2 \mathrm{~A}} \mathrm{R}$ expression in these neurons is not. In fact, the restricted expression of $\mathrm{A}_{2 \mathrm{~A}} \mathrm{R}$ exclusively in enkephalin-positive striatopallidal MSNs has been convincingly demonstrated (Schiffmann et al., 2007; Ferré et al., 2010) and strong evidence against its expression in cholinergic interneurons has recently been provided (Durieux et al., 2009). In the latter work, the authors genetically ablated all striatal neurons that express the adora $2 a$ $\left(\mathrm{A}_{2 \mathrm{~A}} \mathrm{R}\right)$ gene, clearly showing that only striatopallidal neurons degenerate, whereas all types of interneurons, including cholinergic interneurons, remain unaltered (Durieux et al., 2009, their supplemental Fig. 4).

Nevertheless, it is possible to reconcile Tozzi et al.'s (2011) results, and probably those obtained in the previous studies, by considering the presynaptic distribution of $\mathrm{A}_{2 \mathrm{~A}} \mathrm{Rs}$ in glutamatergic terminals, in addition to their postsynaptic expression in $\mathrm{D}_{2}$ striatopallidal MSNs (Fig. 1, blue and gray numbered pathways). $\mathrm{A}_{2 \mathrm{~A}}$ Rs may indeed follow a defined pattern of presynaptic distribution and so modulate glutamate release in direct-pathway corticostriatonigral and thalamostriatal terminals (Schiffmann et al., 2007; Ferré et al., 2010). In line with this view, thalamostriatal terminals have recently been shown to regulate cholinergic interneuron bursting activity in response to salient stimuli, and this modulates the gating of corticostriatal activity and the selective recruitment of $\mathrm{D}_{2}$-striatopallidal MSNs to drive attentional shift (Ding et al., 2010).

All together, emerging studies are clarifying the difficult problem of how a signal initiated in a subset of striatal neurons is able to propagate to all MSNs. As outlined by Tozzi et al. (2011), this complex regulation likely involves almost all known neuromodulatory systems operating in the striatum, from the primary dopamine signal to local eCB-mediated retrograde transmission, going through more tonically propagating signals such as the adenosinergic and acetylcholinergic systems.

\section{References}

Calabresi P, Maj R, Pisani A, Mercuri NB, Bernardi G (1992) Long-term synaptic depression in the striatum: physiological and pharmacological characterization. J Neurosci 12:4224-4233.

Di Filippo M, Picconi B, Tantucci M, Ghiglieri V, Bagetta V, Sgobio C, Tozzi A, Parnetti L, Calabresi P (2009) Short-term and long-term plasticity at corticostriatal synapses: implica- tions for learning and memory. Behav Brain Res 199:108-118.

Ding JB, Guzman JN, Peterson JD, Goldberg JA, Surmeier DJ (2010) Thalamic gating of corticostriatal signaling by cholinergic interneurons. Neuron 67:294-307.

Durieux PF, Bearzatto B, Guiducci S, Buch T, Waisman A, Zoli M, Schiffmann SN, de Kerchove d'Exaerde A (2009) D2R striatopallidal neurons inhibit both locomotor and drug reward processes. Nat Neurosci 12:393-395.

Ferré S, Lluís C, Justinova Z, Quiroz C, Orru M, Navarro G, Canela EI, Franco R, Goldberg SR (2010) Adenosine-cannabinoid receptor interactions: implications for striatal function. Br J Pharmacol 160:443-453.

Gong S, Zheng C, Doughty ML, Losos K, Didkovsky N, Schambra UB, Nowak NJ, Joyner A, Leblanc G, Hatten ME, Heintz N (2003) A gene expression atlas of the central nervous system based on bacterial artificial chromosomes. Nature 425:917-925.

Kreitzer AC, Malenka RC (2007) Endocannabinoidmediated rescue of striatal LTD and motor deficits in Parkinson's disease models. Nature 445:643647.

Olson PA, Tkatch T, Hernandez-Lopez S, Ulrich S, Ilijic E, Mugnaini E, Zhang H, Bezprozvanny I, Surmeier DJ (2005) G-proteincoupled receptor modulation of striatal CaV1.3 L-type Ca2 + channels is dependent on a Shank-binding domain. J Neurosci 25:1050-1062.

Owen GR, Häkkinen L, Wu C, Larjava H (2010) A reproducible technique for specific labeling of antigens using preformed fluorescent molecular IgG-F $\left(\mathrm{ab}^{\prime}\right) 2$ complexes from primary antibodies of the same species. Microsc Res Tech 73:623-630.

Schiffmann SN, Fisone G, Moresco R, Cunha RA, Ferré S (2007) Adenosine A2A receptors and basal ganglia physiology. Prog Neurobiol 83:277-292

Tozzi A, de Iure A, Di Filippo M, Tantucci M, Costa C, Borsini F, Ghiglieri V, Giampà C, Fusco FR, Picconi B, Calabresi P (2011) The distinct role of medium spiny neurons and cholinergic interneurons in the D2/A2A receptor interaction in the striatum: implications for Parkinson's disease. J Neurosci 31:1850-1862.

Wang Z, Kai L, Day M, Ronesi J, Yin HH, Ding J, Tkatch T, Lovinger DM, Surmeier DJ (2006) Dopaminergic control of corticostriatal longterm synaptic depression in medium spiny neurons is mediated by cholinergic interneurons. Neuron 50:443-452. 